\title{
Análise da Adequabilidade do Balanced Scorecard a um Plano Estratégico: Estudo de Caso em um APL - Arranjo Produtivo Local.
}

\author{
Carlos Alberto Kühl \\ Professor Assistente \\ Universidade do Oeste do Paraná \\ Rua Presidente Zacarias, 875 - Santa Cruz \\ 85.010-990 - Guarapuava-PR \\ ckuhl@facc.ufrj.br \\ João Bosco Arbués Carneiro Júnior \\ Professor Assistente \\ Universidade Federal de Mato Grosso \\ Rodovia MT 130 \\ 78.700-000 - Rondonópolis-MT \\ joaobosco@ufmt.br \\ Josemar Ribeiro de Oliveira \\ Professor Assistente \\ Universidade Federal de Mato Grosso \\ Rodovia MT 130 \\ 78.700-000 - Rondonópolis-MT \\ josemar@ufmt.br
}

\section{Resumo}

Este artigo analisa a adequabilidade de um plano estratégico de um Arranjo Produtivo Local (APL) ao Balanced Scorecard (BSC). Para fundamentar os conceitos contidos neste trabalho foi realizada uma pesquisa bibliográfica e uma pesquisa documental para levantar os dados do plano estratégico do APL. O objetivo geral foi o de verificar se os indicadores de desempenho elaborados para o APL podem ser adaptados na estrutura do BSC. para se atender ao objetivo geral foram propostos os objetivos específicos que são: apresentar os indicadores pelo APL, verificar quais desses são absorvidos pela metodologia do BSC e identificar quais os aspectos da metodologia não são abordados. Concluiu-se que os indicadores podem ser adaptados, porém encontram-se incompletos em algumas perspectivas e totalmente inexistentes na perspectiva dos clientes. Verificou-se também a abrangência e a utilidade do BSC como ferramenta de gestão. As reflexões contidas neste trabalho levam a recomendação da utilização do BSC, tendo em vista a abrangência e a utilidade proporcionada por essa ferramenta de gestão.

Palavras-chave: Planejamento Estratégico. Arranjos Produtivos Locais. Balanced Scorecard.

\begin{abstract}
This article examines the suitability of a strategic plan in a Regional Sectoral Cluster (RSC) to the Balanced Scorecard (BSC). To support the concepts in this work, it is presented a literature review and a documentary research to collect data of the RSC strategic plan. The overall objective was to verify whether the performance indicators developed for the RSC can be adapted to the structure of the BSC. In order to achieve the general goal have been proposed Artigo submetido em 3 de março de 2008 e aceito em 18 de setembro de 2008 pelo Editor José Ricardo Maia de Siqueira, após double blind review.
\end{abstract}


specific objectives, they are: to present the indicators for the RSC, see which of these are absorbed by BSC methodology and identify which aspects of the methodology are not addressed. It has been concluded that the indicators can be adapted, but they are incomplete in some perspective and totally non-existent in the customer perspective. It was also observed the scope and usefulness of the BSC as a management tool. The reflections in this work lead to the recommendation of the use of $\mathrm{BSC}$, due to the scope and utility provided by this management tool.

Key-words: Strategic Planning. Regional Sectoral Cluster. Balanced Scorecard.

\section{Introdução}

A internacionalização da economia provocou efeitos prejudiciais à competitividade de pequenas e médias empresas, já que essas, mesmo sem intenção, passaram a competir com grandes corporações internacionais.

Neste contexto uma alternativa para amenizar esse problema foi à busca pela formação de desenvolvimento de redes de cooperação produtiva, para compartilhar experiências e juntar forças para que as mesmas pudessem sobreviver.

Sendo assim, foi criado um ambiente propicio para o surgimento e o desenvolvimento de distritos industriais, de clusters, de aglomerações industriais e de Arranjos Produtivos Locais, conhecidos como APL, que podem ser definidos, de forma inicial, como um tipo especial de cluster. Os conceitos e as definições de cada item, neste parágrafo citado, foram apresentados no primeiro capítulo deste trabalho.

No Brasil, existem atualmente 229 APL's acompanhados pelo SEBRAE, uma das instituições responsáveis pela criação e desenvolvimento desses arranjos. Como em qualquer atividade empresarial, os APL's necessitam de planejamento e controle, para que os seus gestores possam avaliar e medir o desempenho.

Várias são as formas de avaliação do desempenho empresarial, dentre essas, a que merece destaque é o Balanced Scorecard (BSC), proposto por KAPLAN e NORTON no início dos anos 90, que tem por objetivo traduzir a missão e a estratégia num conjunto abrangente de medidas de desempenho que servem de base para um sistema de medição e de gestão estratégica (KAPLAN e NORTON, 1996 p. 02.)

Contudo, pretende-se nesse trabalho verificar se os indicadores de desempenho elaborados pelo grupo gestor de um APL pode ser adaptado à metodologia do $B S C$, para tanto é necessário especificamente apresentar os indicadores elaborados pelo APL, verificar quais desses são absorvidos pela metodologia do $B S C$ e identificar quais os aspectos da metodologia não são abordados por esses indicadores.

Vale aqui enfatizar, que em nenhum momento pretende-se externar uma opinião avaliativa do planejamento elaborado pelo grupo gestor do APL e sim, conforme os objetivos acima citados, refletir o planejamento estratégico em uma importante ferramenta de gestão, enfatizando e demonstrando a utilidade do $B S C$, como um instrumento mais abrangente, completo e relevante.

O trabalho está dividido em seis partes, além dessa introdução, a primeira consiste na apresentação do APL como alternativa para o desenvolvimento sustentável, seguido por um capítulo sobre $B S C$, que contempla suas características, objetivos e perspectivas, segue-se com um capítulo destinado a enunciar a metodologia utilizada no trabalho, um capítulo destinado a caracterizar o APL em estudono próximo são adaptados os indicadores do APL à metodologia do $B S C$ e por fim foram enunciadas as considerações finais sobre a pesquisa. 


\section{Arranjos Produtivos Locais}

Primeiramente é necessário situar os APL's dentro de um contexto maior, sendo assim, o passo inicial é conceituar as aglomerações. Albagli e Brito (2003, p.7) ensinam que as aglomerações possuem como aspecto central à proximidade territorial de agentes políticos, econômicos e sociais.

Como se observa, esta definição é bastante ampla, sendo esse o motivo que leva a ser enunciada inicialmente, a partir daí, pode-se conceituar um outro tipo, mais específico, denominado clusters. Segundo Lastres; Cassiolato; Maciel (2003, p. 2) estes são caracterizados pelas interações tecnológicas em torno de diferentes modos de aprendizado culturalmente delimitados. Para Porter apud SEBRAE (2004, p.229)

os clusters são concentrações geográficas de empresas - similares, relacionadas ou complementares - que atuam na mesma cadeia produtiva auferindo vantagens de desempenho por meio da locação e, eventualmente, da especialização. Essas empresas partilham, além da infra-estrutura, o mercado de trabalho especializado e confrontam-se com oportunidades e ameaças comuns.

Para reconhecer um aglomerado como cluster, é necessário verificar a existência de aspectos setoriais e geográficos comuns. Para amenizar a dificuldade de distinguir clusters de aglomerados, Humphrey e Schmitz apud Amato Neto (2000, p. 54) desenvolveram um conjunto de fatores facilitadores, que são:

- Divisão do trabalho e da especialização entre produtores;

- Estipulação da especialidade de cada produtor;

- Surgimento de fornecedores de matéria-prima e de máquinas;

- Surgimento de agentes que vendam para mercados distantes;

- Surgimento de empresas especialistas em serviços tecnológicos, financeiros e contábeis;

- Surgimento de uma classe de trabalhadores assalariados com qualificações e habilidades específicas;

- Surgimento de associações para a realização de lobby e de tarefas específicas para o conjunto de seus membros.

Após a contextualização de aglomerações e de clusters, pode-se apresentar os APL's, dentro da definição dada pelo $\operatorname{SEBRAE}(2004$, p. 9) aonde ele traz que o

APL é um tipo particular de cluster formado por pequenas e médias empresas, agrupadas em torno de uma profissão ou de um negócio, onde se enfatiza o papel desempenhado pelos relacionamentos - formais e informais - entre empresas e demais instituições envolvidas. As firmas compartilham uma cultura comum, como um grupo, com ambiente sócio-cultural local.

Para a Rede de Pesquisa em Sistemas Produtivos e Inovativos Locais (apud LASTRES, CASSIOLATO, 2003, p. 10-11), grupo de pesquisa vinculado ao Instituto de Economia da Universidade Federal do Rio de Janeiro, APL's

são aglomerações territoriais de agentes econômicos, políticos e sociais - com foco em um conjunto específico de atividades econômicas - que apresentam vínculos mesmo que incipientes. Geralmente envolvem a participação e a interação de empresas - que podem ser desde produtoras de bens e serviços finais, até fornecedoras de insumos e equipamentos, prestadoras de consultoria e serviços, comercializadoras, clientes, entre outros - e suas variadas formas de representação e associação. Incluem também diversas outras instituições públicas e privadas, voltadas para: formação e capacitação de recursos humanos (como escolas técnicas e universidades); pesquisa, desenvolvimento e engenharia; política, promoção e financiamento.

Contribuindo com essas definições Santos; Guarneri (2004, p. 197) conceituam APL's um fenômeno vinculado às economias de aglomeração, associada à proximidade física das empresas fortemente ligadas entre si por fluxos de bens e serviços. 
Corrobora com a definição do SEBRAE, em evidenciar que o APL é um tipo especial de cluster, Santos; Diniz; Barbosa (2004, p. 12) aonde trazem as peculiaridades que os arranjos produtivos locais tem em relação ao cluster

É necessária a presença de fornecedores especializados, universidades, associações de classe e instituições governamentais pró-ativas no local, centros tecnológicos, centros de treinamento de mão-de-obra, ou instituições que façam coleta e difusão de informação, apoio técnico, ou ainda elevado grau de cooperação, confiança ou inovação local.

Os APL's são justificados na medida em que contribuem para o desenvolvimento local integrado e sustentável, atendendo para o aumento de competitividade de micro e pequenas empresas de um mesmo território e setor. Os objetivos esperados de políticas focadas em APL's são:

- Contribuir para viabilizar a cooperação entre agentes, gerando externalidades positivas associadas às economias de aglomeração;

- Contribuir para ampliar as condições de competitividade e sustentabilidade de economias regionais;

- Apoiar ações que estabeleçam e potencializem processos de aprendizado e inovação em APLS's;

- Fomentar, em escala regional, parcerias entre empresas e entre estas e órgão governamentais, instituídos de P\&D e universidades, contribuindo para o fortalecimento de Arranjos Produtivos Locais;

- Contribuir para a solução de problemas econômicos e sociais, promovendo o desenvolvimento local, com ênfase na geração de emprego e renda, na promoção das exportações e na substituição de importações (MCT, 2005).

Espera-se, que a fomentação e o empenho no desenvolvimento de APL's tragam resultados satisfatórios para as empresas participantes, para a cadeia produtiva e como fim, benefícios almejados que alcancem a sociedade como um todo.

O enfoque dado aos APL's traz vantagens competitivas para seus participantes e para a sociedade como fim. As principais vantagens são encontradas em Santos; Diniz; Barbosa (2004, p. 173)

- Conhecimento tácito compartilhado entre as empresas, os fornecedores os clientes e/ou a mão-de-obra;

- Capacidade de as empresas locais obterem ganhos significativos advindos da boa imagem regional no mercado e cooperarem para conseguir investimentos públicos e evitar atitudes oportunistas que possam comprometer a imagem regional;

- Cooperação institucionalizada com capacidade de induzir a reação coletiva a ameaças e oportunidades e capaz de mobilizar entidades governamentais e levantar recursos de forma de conseguir vantagens competitivas para as firmas associadas (pode ser pelo oferecimento de serviços complementares, pela atração de investimentos públicos ou pelo apoio ao desenvolvimento competitivo dos associados);

- Incentivos fiscais, custos de mão-de-obra e logística de transporte;

- Acesso a produtos, serviços ou ativos complementares específicos importantes para as empresas locais, o qual pode ser disponibilizado por relações comerciais e societárias, por cooperação informal, por cooperação institucionalizada ou por entidades governamentais;

- A cooperação multilateral (institucionalizada) é importante para a capacidade de reação coletiva a ameaças e oportunidades graças ao planejamento e à atuação da cooperação institucionalizada.

Verifica-se através das vantagens acima apresentadas, a utilidade social dos APL's, todavia para seu desenvolvimento e conseqüente sucesso, algumas premissas devem ser observadas, para Santos; Diniz; Barbosa (2004, p. 175) os principais fatores destacados como de grande importância para o desenvolvimento dos APL's são: 
- As sedes administrativas das empresas estarem no APL;

- Uma parte significativa das decisões de financiamento para investimento estar no APL (com capital próprio ou de terceiros);

-Não pertencer a sistemas industriais periféricos;

-A propriedade de marcas e tecnologia de produtos ser principalmente de empresas cuja sede está no APL;

- O desenvolvimento de produtos ser realizado no APL;

- O desenvolvimento de máquinas e insumos especializados ser realizado no APL;

- A cooperação institucionalizada oferecer serviços fundamentais;

- Sensibilidade de entidades governamentais às necessidades do APL e estreita cooperação entre essas entidades e o representante das empresas (raramente o item anterior pode se desenvolver plenamente sem apoio do governo e incentivos públicos ao livre acesso aos serviços prestados pela cooperação institucionalizada);

- Presença de instituições de desenvolvimento tecnológico no APL;

- Planejamento estratégico permanente e participativo no APL;

- Acesso à mão-de-obra especializada e capacitada para atividades criativas ou estratégicas do setor; e

- Grau de confiança mútua preexistente no local.

Finaliza-se este capítulo, destinado exclusivamente à caracterização de APL's, reforçase, agora com embasamento teórico, a idéia que o foco em arranjos produtivos locais pode trazer benefícios à sociedade como um todo, provocando o desenvolvimento local, integrado e sustentável. Entretanto, este possui certas premissas tanto para identificação, quanto para o desenvolvimento e fortalecimento do aglomerado que devem receber uma atenção especial perante aos órgãos gestores e também dos órgãos públicos.

\section{Balanced Scorecard}

Atualmente as empresas buscam por novas capacidades para assegurar o sucesso num mercado cada vez mais competitivo, que exige da administração uma nova postura, com a finalidade de buscar vantagem competitiva. Isto pode ser alcançado através da gestão empresarial, utilizando-se de ferramentas, como por exemplo o planejamento das atividades.

O planejamento, conforme Oliveira (1999, p. 33) "é um processo decisório que ocorrerá antes, durante e depois de sua elaboração e implementação na empresa", ou seja, um processo contínuo de acompanhamento das atividades da empresa.

Desde o início da década de 70, conforme relato de Gaj (1990, p. XXIII), já se encontram trabalhos publicados a respeito da utilização da estratégia, juntamente com o planejamento, com o intuito de melhor administrar as atividades da empresa.

Como estratégia, conforme ensinam Iudícibus e Marion (2001, p. 87), deve-se entender que é um

processo de seleção dos segmentos de mercado e de cliente, identificação dos processos críticos, internos e externos do negócio nos quais a empresa precisa destacar-se para melhorar o valor ao cliente e seleção das competências individuais e organizacionais necessárias para atingir-se os objetivos financeiros, do cliente e da empresa.

Como seqüência lógica destes avanços, surge o planejamento estratégico, que nas palavras de Almeida (2001, p. 13)

É uma técnica administrativa que procura ordenar as idéias das pessoas, de forma que se possa criar uma visão do caminho que se deve seguir (estratégia). Depois de ordenar as idéias, são ordenadas as ações, que é a implementação do Plano Estratégico, para que, sem desperdício de esforços, caminhe na direção pretendida.

Entretanto, com frequiência o controle deste planejamento estratégico não estava cumprindo de forma integral a sua missão de contínuo acompanhamento das atividades da 
empresa, pois o seu desempenho era avaliado por relatórios financeiros, esquecendo-se, se não por completo, mas relegando ao segundo plano, os aspectos não-financeiros descritos na estratégia e no próprio planejamento estratégico da empresa. Além disso, "os indicadores financeiros apenas mostram conseqüências de decisões já tomadas e não tendências para o futuro." (KALLAS, 2003, p. 17)

"Surge então como complemento das medidas de desempenho não-financeiras, o conceito de Balanced Scorecard, objetivando unir a visão estratégica com as fases de execução e controle do processo de gestão empresarial" (PADOVEZE, 2003, p.121).

O Balanced Scorecard (BSC), de acordo com Bruni e Famá (2003, p. 375) consiste em um conjunto integrado de medidas de desempenho decorrentes da estratégia da empresa e que dão suporte a essa estratégia em toda a organização.

O BSC, criado por Kaplan e Norton, procura medir o desempenho da empresa através de indicadores financeiros e não-financeiros. Porém como os próprios autores relatam, "os objetivos e medidas utilizados no BSC não se limitam a um conjunto aleatório de medidas de desempenho financeiro e não-financeiro, pois derivam de um processo hierárquico (top-down) norteado pela missão e pela estratégia da unidade de negócios." (KAPLAN e NORTON, 1997, p.9).

Pode-se verificar na figura 01 o relacionamento traduzindo a missão da organização em resultados almejados.

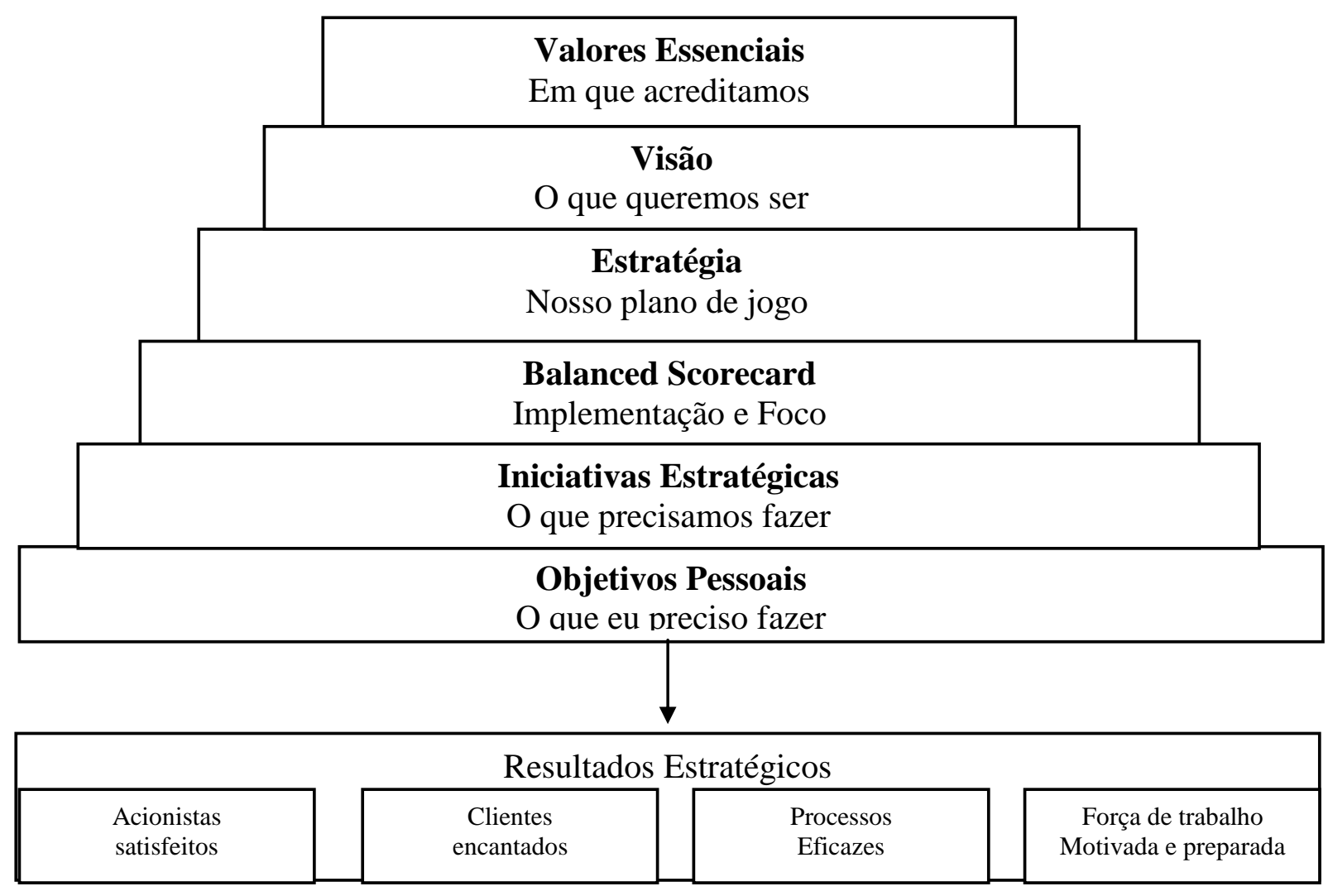

Fonte: Kaplan e Norton (2001, p. 85)

Figura 1: Traduzindo a missão em resultados almejados

Mais do que um sistema de medidas táticas ou operacionais, o BSC pode ser visto como um sistema de gestão estratégica para administrar a estratégia a longo prazo, de acordo com Kaplan e Norton, pois as empresas utilizam-se dele para viabilizar processos gerenciais críticos (figura 02). 


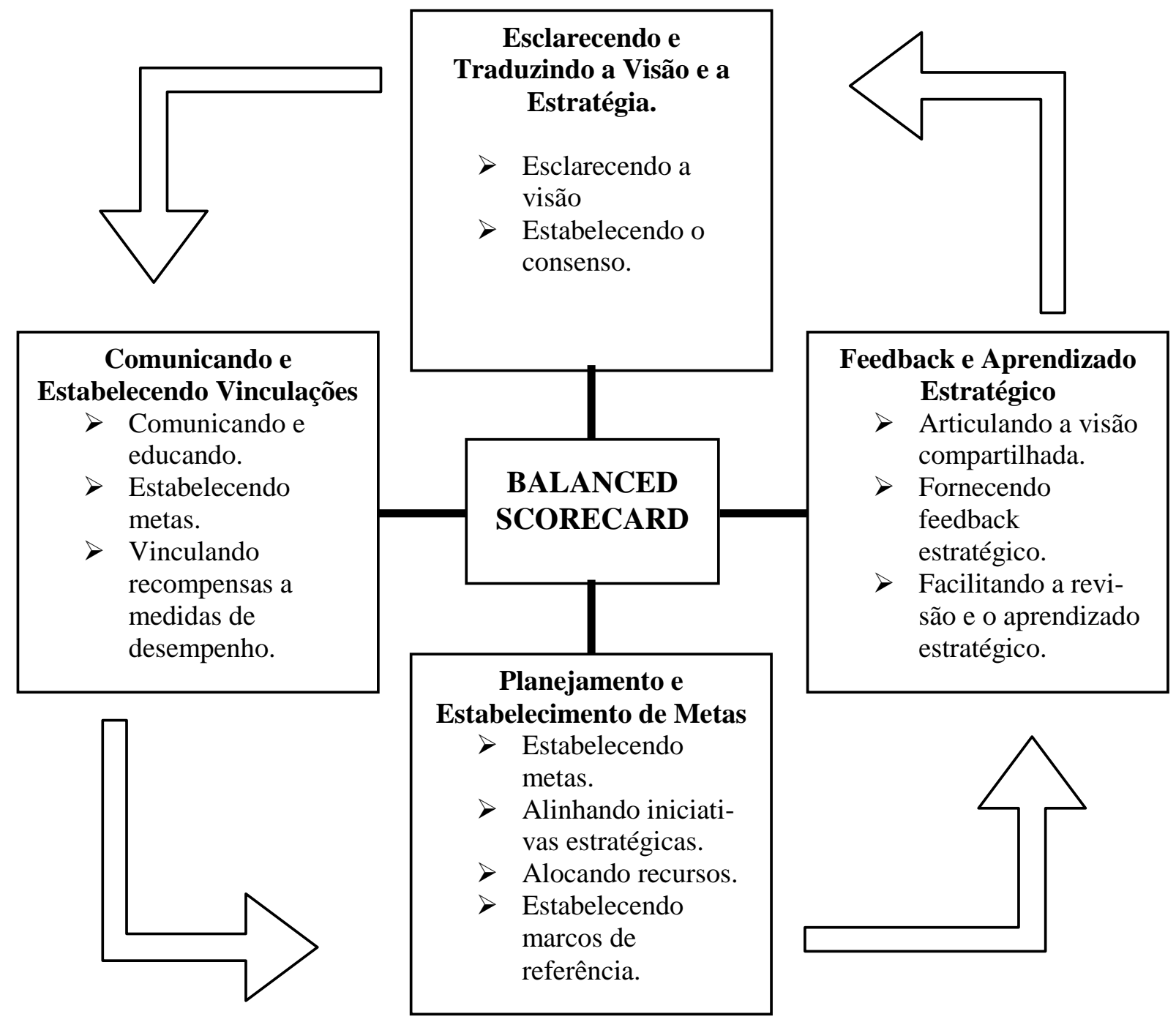

Fonte: Kaplan e Norton (1997, p. 12)

Figura 2 - O Balanced Scorecard como Estrutura para Ação Estratégica

Em outras palavras, pode-se dizer que o $B S C$ é meio pelo qual a missão é compartilhada com toda a organização e um modelo para a descrição de estratégias que criam valor para a organização.

O BSC procura decompor a estratégia de uma forma lógica, baseada relações de causa e efeito, vetores de desempenho e relação com os fatores financeiros (KAPLAN e NORTON, 1997, p.155). Deve ser decomposto em objetivos, indicadores, metas e iniciativas, em quatro dimensões de negócio: financeira, clientes, processos internos e aprendizado e crescimento. 


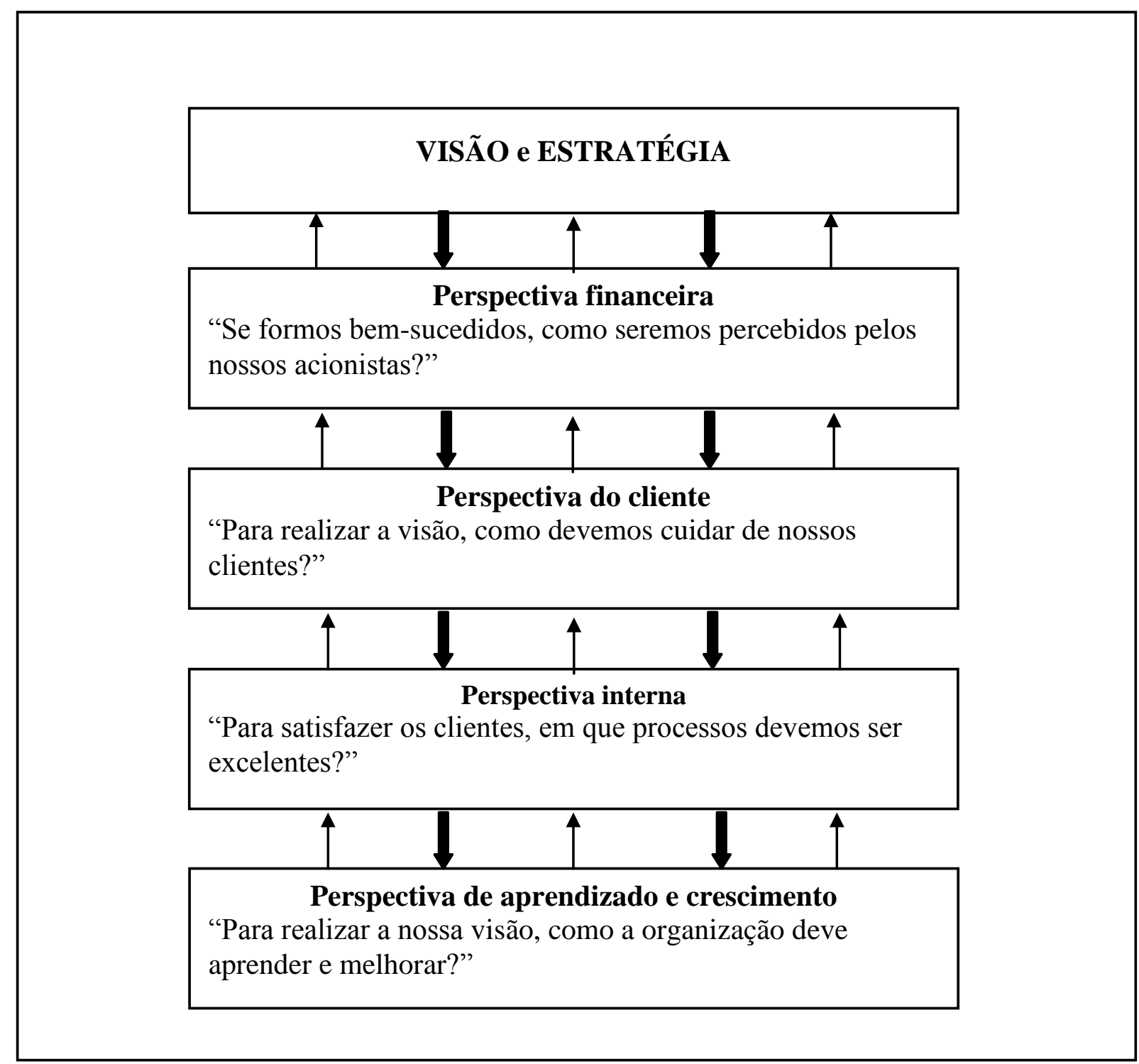

Fonte: Adaptado de Kaplan e Norton (2001, p.89)

Figura 3: Definindo as relações de causa-efeito da estratégia

A perspectiva financeira para Kaplan e Norton (2004, p.33) “define a cadeia lógica pela qual os ativos intangíveis serão convertidos em valor tangível”. Os objetivos financeiros serão o foco das demais perspectivas. Também para Kaplan e Norton (1997, p.49) a "elaboração do BSC deve ser um incentivo para que as unidades de negócios vinculem seus objetivos financeiros à estratégia da empresa". Os objetivos financeiros possuem uma interação com os demais, em virtude da necessidade por parte das empresas, em tornarem rentáveis as suas operações.

A perspectiva dos clientes "esclarece as condições que criarão valor para os clientes" (KAPLAN e NORTON, 2004, p. 33). Deve-se definir nesta perspectiva os clientes e mercados nos quais a empresa deseja competir. As empresas devem ter como atividade essencial à satisfação das necessidades dos clientes. "O BSC, sob este aspecto deve buscar indicadores que evidenciem os resultados (positivos ou negativos) no atendimento desta expectativa, desde que se relacionem com a estratégia estabelecida pela empresa para ir ao mercado." (ROCHA, 2002, p. 58) 
A perspectiva dos processos internos, segundo Kaplan e Norton (2004, p.33) "identifica os processos que transformarão ativos intangíveis em resultados para os clientes e em resultados financeiros". Nesta perspectiva são estabelecidos os objetivos e medidas, ou seja um conjunto específico de processos com a finalidade de criar valor para os clientes e produzir resultados financeiros. Segundo Kaplan e Norton esses processos são subdivididos em gestão operacional, gestão de clientes, gestão de inovação e gestão dos processos regulatórios e sociais.

A perspectiva de aprendizado e crescimento "determina os ativos intangíveis a serem alinhados e integrados para criar valor" (KAPLAN e NORTON, 2004, p.33). Esses ativos intangíveis podem ser classificados em três categorias, a saber: capital humano, capital da informação e capital organizacional. Nesta perspectiva busca-se a implementação de medidas que direcionem o funcionamento da infra-estrutura da empresa.

Em cada uma das perspectivas acima, encontram-se os objetivos, que representam aonde queremos chegar; os indicadores, que servem para medir o desempenho dos objetivos; as metas, que apresentam o nível desejado dos indicadores e as iniciativas, que são as atitudes a serem tomadas para que se possam alcançar os objetivos propostos.

É através do constante acompanhamento dos indicadores apresentados pelo BSC que se pode avaliar o desempenho da empresa e verificar se a mesma está apta a alcançar os seus objetivos estratégicos e a cumprir a sua missão.

\section{Metodologia}

No artigo foi utilizado dados fornecidos pelo grupo gestor do APL, tais informações foram retiradas do planejamento estratégico elaborado sobre a forma de apresentação. Quando há utilização de documentos que não foram trabalhados, a pesquisa é caracterizada como documental. A pesquisa documental, segundo Gil (2002, p. 47) é importante não porque respondem definitivamente a um problema, mas porque proporcionam melhor visão desse problema ou, então, hipóteses que conduzem a sua verificação por outros meios.

Para conceituar e embasar a fundamentação teórica da pesquisa, este trabalho utilizou livros, artigos e trabalhos nacionais e internacionais caracterizando o artigo como uma pesquisa bibliográfica. Para Gil (2002, p. 44) a pesquisa bibliográfica é desenvolvida com base em material já elaborado, constituído principalmente de livros e artigos científicos.

Contudo, pode-se afirmar que o presente estudo é uma pesquisa bibliográfica, que utiliza o método de pesquisa bibliográfico. As técnicas para coleta de informações foram a pesquisa documental e a bibliográfica.

\section{Arranjo Produtivo Local em Estudo}

O APL em estudo é composto por treze indústrias de confecções formais, informais e os núcleos de fiação, tingimento e tecelagem manual, existente em um Município brasileiro.

As indústrias de confecções formais são compostas por micro e pequenas empresas e os núcleos de fiação, tingimento e tecelagem manual encontram-se em uma cooperativa de produção com cerca de vinte e cinco cooperados.

$\mathrm{Na}$ base territorial do município são produzidos, segundos dados da Prefeitura Municipal, aproximadamente 40.000 toneladas de algodão em uma área de 12.000 hectares.

A criação deste APL se deu por volta do ano de 2002 através de uma iniciativa nacional de desenvolvimento local, integrado e sustentável, com o objetivo de sistematizar APL's em territórios que possuem as características para a sua formação.

A definição por um APL em confecções, por parte das instituições competentes, motivou-se pelos seguintes aspectos: a produção de algodão existente no Município, a 
quantidade de empresas já instaladas, o número de empregos gerados e a possibilidade de crescimento e desenvolvimento do setor.

As indústrias de confecções sejam formais ou informais, compram a matéria-prima geralmente do Estado de Minas Gerais ou do Estado do Paraná, em virtude de não haver na região uma indústria têxtil capaz de atendê-los, apesar da grande produção de algodão supracitada. Os produtos são fabricados de acordo com os pedidos feitos pelos clientes, ou seja, por ordem de produção. Os principais produtos fabricados são uniformes profissionais e escolares. Os clientes são formados pelas empresas do agronegócio e pela rede escolar do Município e região.

Os núcleos de fiação, tingimento e tecelagem manual trabalham com algodão natural, adquirido no próprio Município, aonde, o mesmo é transformado em fio e este resultará nos produtos a serem comercializados. Os produtos fabricados são: almofadas, xales, mantas, entre outros. Devido a essa produção ser artesanal os produtos ganham uma caracterização da região, sendo assim, os clientes são os turistas que visitam o Município e grande parte dos produtos são remetidos para feiras e eventos em todo o território nacional.

\section{Planejamento Estratégico do APL em Estudo}

A gestão do APL é feita por um grupo gestor composto por oito entidades, formalizadas por um termo de cooperação técnica (SEBRAE, Sindicato de indústrias de confecções, Associação Comercial, um fundo de apoio ao algodão, Prefeitura Municipal, SENAI, Banco do Brasil e Caixa Econômica Federal).

O grupo gestor apresentou uma proposta de planejamento de acordo com o diagnóstico da situação das empresas:

\section{DIAGNÓSTICO}

1. Dificuldade de definir os custos e determinar o preço de venda.

2. Desconhecimento de mercado em âmbito nacional e internacional.

3. Falta de mão-de-obra qualificada em costura industrial.

4. Sistema operacional de controle e gestão não informatizado.

5. Falta de visão estratégica de negócios.

6. Necessidade de fortalecimento das lideranças.

7. Baixa produtividade.

8. Necessidade de fortalecimento do comportamento empreendedor.

Fonte: Adaptado do Planejamento Estratégico do APL.

Quadro 1: Diagnóstico Estratégico do APL

A partir desse diagnóstico foi elaborado um mapa com os desafios e os focos estratégicos relacionados com a situação levantada. 


\begin{tabular}{|c|c|}
\hline & ESTI \\
\hline $\begin{array}{l}\text { 1. Capacitar a empresa em formação de } \\
\text { preços competitivos. }\end{array}$ & $\begin{array}{l}\text { 1. Desenvolver produtos a custos } \\
\text { competitivos. }\end{array}$ \\
\hline nelhor os mercados pot & $\begin{array}{l}\text { 2. Reposicionar produtos com relação a } \\
\text { nichos de mercados. }\end{array}$ \\
\hline $\begin{array}{l}\text { 3. Capacitar as empresas em níveis de } \\
\text { supervisão e operacional. }\end{array}$ & $\begin{array}{l}\text { 3. Desenvolver treinamentos para qualificação } \\
\text { de mão-de-obra e capacitação gerencial. }\end{array}$ \\
\hline 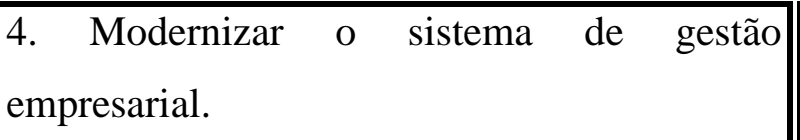 & $\begin{array}{l}\text { 4. Implantar sistema informatizado de gestão } \\
\text { empresarial. }\end{array}$ \\
\hline \begin{tabular}{llll|}
5. & Capacitar as empresas em gestão \\
estratégica de negócios. & & \\
\end{tabular} & $\begin{array}{l}\text { 5. Desenvolver treinamento em gestão } \\
\text { estratégica de negócios. }\end{array}$ \\
\hline 6. Fortal & e governanças. \\
\hline 7. Aumentar a eficácia do processo produtivo. & 7. Racionalizar o processo produtivo. \\
\hline 8. Desenvolver o empreendedorismo no APL. & $\begin{array}{l}\text { 8. Desenvolver ações de estímulo ao } \\
\text { empreendedorismo. }\end{array}$ \\
\hline & \\
\hline
\end{tabular}

Com base no diagnóstico realizado e nos desafios propostos, além dos focos estratégicos estabelecidos, o grupo gestor enunciou o seguinte objetivo geral "aumentar o faturamento, a produtividade e a qualidade das empresas do APL", tendo como resultado final elevar o faturamento das empresas em $50 \%$ e reduzir o retrabalho em $15 \%$. Para isso as seguintes premissas devem ser observadas:

a)- crescimento econômico anual (país e estado) não inferior a 2,5 \% ao ano;

b)- estabilidade econômica, com inflação inferior a dois dígitos, situada entre 6 e $9 \%$ ao ano;

c)- manutenção da taxa cambial favorável à exportação, não inferior a R \$ 2,80/US\$;

d)- taxa de juros com tendência de queda;

e)- permanência dos incentivos do ICMS.

Observando os focos estratégicos enunciados pelo grupo gestor do APL e atendendo os objetivos propostos neste trabalho, na figura 4 a seguir é feita uma adaptação dos focos estabelecidos a um mapa estratégico segundo a metodologia do BSC. 


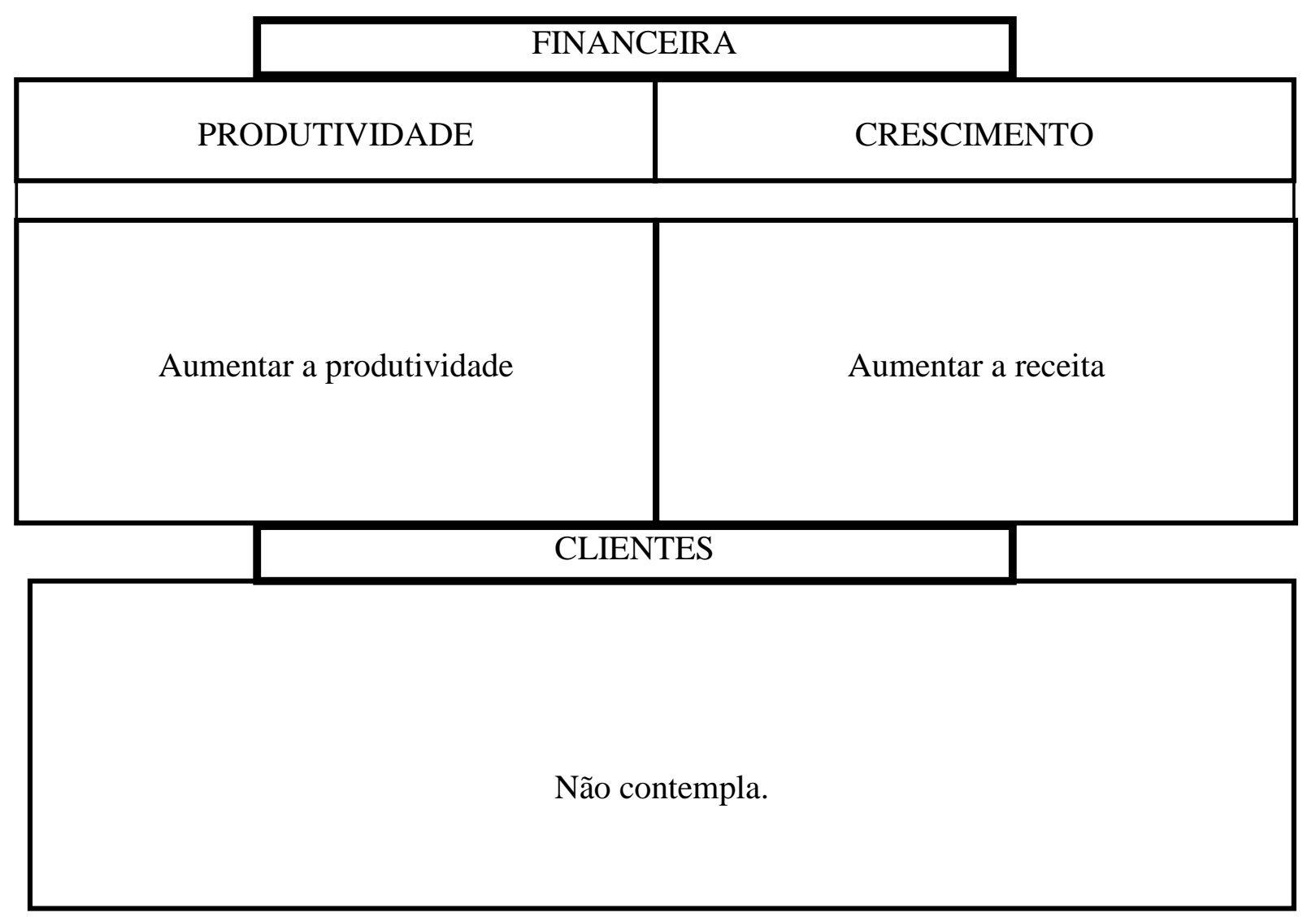

\begin{tabular}{|c|c|c|c|c|}
\hline \multicolumn{4}{|c|}{ PROCESSOS INTERNOS } & \\
\hline $\begin{array}{c}\text { GESTÃO } \\
\text { OPERACIONAL }\end{array}$ & $\begin{array}{l}\text { GESTÃO DE } \\
\text { CLIENTES }\end{array}$ & \multicolumn{2}{|c|}{ INOVAÇÃO } & $\begin{array}{c}\text { REGULATÓRIO } \\
\text { E SOCIAL }\end{array}$ \\
\hline $\begin{array}{l}\text { 1) Desenvolver } \\
\text { produtos a custos } \\
\text { competitivos. } \\
\text { 2) Racionalizar } \\
\text { processos produtivos. }\end{array}$ & $\begin{array}{l}\text { 1) Reposicionar } \\
\text { produtos com relação } \\
\text { a nichos de mercados. }\end{array}$ & \multicolumn{2}{|c|}{ Não é contemplado } & Não é contemplado \\
\hline \multicolumn{5}{|c|}{ APRENDIZADO E CRESCIMENTO } \\
\hline $\begin{array}{l}\text { CAPITAL } \\
\text { HUMANO }\end{array}$ & \multicolumn{2}{|c|}{$\begin{array}{l}\text { CAPITAL DA } \\
\text { INFORMAÇÃO }\end{array}$} & \multicolumn{2}{|c|}{$\begin{array}{c}\text { CAPITAL } \\
\text { ORGANIZACIONAL }\end{array}$} \\
\hline $\begin{array}{l}\text { 1) Desenvolver treina- } \\
\text { mentos para qualificação } \\
\text { de mão-de-obra e capaci- } \\
\text { tacão gerencial. } \\
\text { 2)- Desenvolver treina- } \\
\text { mento e gestão estratégica } \\
\text { de negócios. }\end{array}$ & \multicolumn{2}{|c|}{$\begin{array}{l}\text { 1)- Implementar sistema } \\
\text { informatizado de gestão } \\
\text { empresarial. }\end{array}$} & \multicolumn{2}{|c|}{$\begin{array}{l}\text { 1)- Desenvolver lideranças e } \\
\text { governança. } \\
\text { 2)- Desenvolver ações de } \\
\text { estímulo ao empreendedorismo. }\end{array}$} \\
\hline
\end{tabular}

Fonte: Elaborado pelos autores.

Figura 4 - Adaptação dos focos estratégicos do APL à metodologia do BSC

Análise da Adequabilidade do Balanced Scorecard a um Plano Estratégico: Estudo de caso em um... 
Após a adaptação do mapa estratégico, segundo a metodologia, o próximo passo é a elaboração do Balanced Scorecard propriamente dito, que compreende o relacionamento das perspectivas com os objetivos e seus respectivos indicadores.

No caso específico deste trabalho, este item não é concebido conforme a metodologia de Kaplan e Norton, e sim, é feita uma adaptação dos focos estratégicos e dos resultados finais almejados, definidos pelo grupo gestor do APL em estudo para o Balanced Scorecard propriamente dito. Pode-se observar esta adaptação no quadro abaixo:

\begin{tabular}{|c|c|c|}
\hline Perspectivas & $\overline{\text { Objetivos }}$ & Indicadores \\
\hline \multirow[t]{2}{*}{ Financeira } & Elevar o faturamento & $\begin{array}{l}\text { Faturamento do mês/ faturamento do } \\
\text { mês base }\end{array}$ \\
\hline & Elevar a produtividade & Tempo de produção \\
\hline \multicolumn{3}{|l|}{ Clientes } \\
\hline \multirow{3}{*}{$\begin{array}{l}\text { Processos } \\
\text { Internos }\end{array}$} & $\begin{array}{llll}\text { Desenvolver produtos a custos } \\
\text { competitivos }\end{array}$ & \\
\hline & Racionalizar o processo produtivo & Número de unidades rejeitadas \\
\hline & $\begin{array}{l}\text { Reposicionar produtos com relação a } \\
\text { nichos de mercados }\end{array}$ & \\
\hline \multirow{5}{*}{$\begin{array}{l}\text { Aprendizado } \\
\text { e Crescimento }\end{array}$} & $\begin{array}{l}\text { Desenvolver treinamentos para } \\
\text { qualificação de mão-de-obra e } \\
\text { capacitação gerencial }\end{array}$ & \\
\hline & $\begin{array}{l}\text { Desenvolver treinamento e gestão } \\
\text { estratégica de negócios }\end{array}$ & \\
\hline & $\begin{array}{l}\text { Implementar sistema informatizado } \\
\text { de gestão empresarial }\end{array}$ & \\
\hline & Desenvolver lideranças e governança & \\
\hline & $\begin{array}{l}\text { Desenvolver ações de estímulo ao } \\
\text { empreendedorismo }\end{array}$ & \\
\hline
\end{tabular}

Fonte: Elaborado pelos autores.

QUADRO 3: Balanced Scorecard elaborado com os dados do APL em Estudo 
Pode-se observar, entretanto, que no BSC que reflete o plano estratégico do APL não é abordada a perspectiva de clientes, sinalizando uma limitação do plano estratégico. Verificase também a ausência de indicadores para a maioria dos objetivos.

\section{Considerações Finais}

Pode-se verificar a relação existente entre o plano estratégico do APL e a estrutura apresentada do BSC, demonstrando a flexibilidade deste instrumento e atendendo o objetivo geral do presente artigo.

Verifica-se a ausência da plena definição da estratégia para o referido APL, uma vez que não é definida claramente sua missão. O que demonstra certa limitação do processo de planejamento estratégico, tendo em vista que esse é o passo inicial para a implementação de qualquer sistemática de planejamento.

Foi evidenciado que a perspectiva financeira do BSC adaptado foi a única a conter objetivos e indicadores relacionados entre si, que possibilita uma avaliação do desempenho do APL em busca da consecução de seus objetivos. Dos três objetivos propostos na perspectiva de processos internos, apenas um foi relacionado com indicador de desempenho. Já os cincos objetivos da perspectiva de aprendizado e crescimento, nenhum contêm indicador relacionado, deixando assim, a impossibilidade de acompanhar o desempenho das ações a serem desenvolvidas, conforme o proposto no plano estratégico.

Na perspectiva de clientes, não foi abordado nenhum objetivo, conseqüentemente não há indicador para esta perspectiva. Considerando que a principal função das empresas deveria ser a satisfação de seus clientes e através dela poder realizar os objetivos financeiros, percebese que esse plano estratégico ao deixar de contemplar a perspectiva de clientes, tanto no que diz respeito aos objetivos como aos indicadores, poderá não alcançar o seu objetivo final.

Através desta adaptação, pode-se observar que não há uma correlação entre as perspectivas, ou seja, entre os objetivos, os indicadores e as metas. Demonstrando assim que não há um esforço único para se atingir os objetivos propostos. Essa sistemática de correlação é uma das características fundamentais do BSC, que o difere de outras sistemáticas de planejamento e controle, tornando-o uma metodologia útil, importante e de grande valia para as entidades em seu processo de gestão.

Todavia é válido reafirmar que o objetivo deste trabalho, em momento algum, é externar uma opinião sobre a coerência do plano estratégico elaborado pelo seu Grupo Gestor e sim demonstrar a flexibilidade de uma sistemática mais abrangente e completa, denominada BSC, que facilita o planejamento estratégico atingir sua plenitude.

As reflexões contidas neste artigo demonstram que o problema de pesquisa foi respondido e os objetivos atingidos. Com base neste fato e conforme observado no desafio estratégico número 4, identificado pelo grupo gestor como modernizar o sistema de gestão empresarial, conclui-se que se pode recomendar pela utilização do BSC, tendo em vista a abrangência a e utilidade, proporcionada por essa ferramenta de gestão.

\section{Referências}

ALBAGLI, Sarita; BRITO Jorge (org.). Glossário de Arranjos e Sistemas Produtivos e Inovativos Locais. Rio de Janeiro: RedeSist, 2003.

ALMEIDA, Martinho Isnard Ribeiro de. Manual de Planejamento Estratégico. São Paulo: Atlas, 2001.

\footnotetext{
AMATO NETO, João. Redes de Cooperação Produtiva e Clusters Regionais: oportunidades para as pequenas e médias empresas. São Paulo: Atlas, 2000.
} 
BRUNI, Adriano Leal; FAMÁ, Rubens. Gestão de Custos e Formação de Preços. São Paulo: Atlas, 2003.

GAJ, Luis. Tornando a Administração Estratégica Possível. São Paulo: McGraw-Hill, 1990.

GIL, Antônio Carlos. Como Elaborar Projetos de Pesquisa. 4. ed. São Paulo: Atlas, 2002.

IUDÍCIBUS, Sérgio de; MARION, José Carlos. Dicionário de Termos de Contabilidade. São Paulo: Atlas, 2001.

KALLAS, David. Balanced Scorecard: aplicação e impactos. Um estudo com jogos de empresas. Dissertação (Mestrado em administração). FEA/USP, São Paulo, 2003.

KAPLAN, Robert S.; NORTON, David P. Mapas Estratégicos. Rio de Janeiro: Campus, 2004.

KAPLAN, Robert S.; NORTON, David P. Organizações Orientadas para a Estratégia: Como Empresas que Utilizam o Balanced Scorecard prosperam no novo ambiente de negócios. 4. ed. Rio de Janeiro: Campus, 2001.

KAPLAN, Robert S.; NORTON, David P. A Estratégia em Ação: Balanced Scorecard. Rio de Janeiro: Campus, 1996.

LASTRES, Helena M. M.; CASSIOLATO, José E.; MACIEL, Maria Lúcia (org.). Pequena Empresa: Cooperação e Desenvolvimento Local. Rio de Janeiro: Relume Dumará, 2003.

LASTRES, Helena M. M.; CASSIOLATO, José E. Novas Políticas na era do Conhecimento: O Foco em Arranjos Produtivos e Inovativos Locais, Revista Parcerias Estratégicas, fev. 2003.

MCT - MINISTÉRIO DA CIÊNCIA E TECNOLOGIA . Arranjos Produtivos Locais, 2002, Brasília. Disponível em: <http://www.mct.gov.br/Fontes/Fundos/Documentos/CTFVA/ ctfva03arranjos_produtivos.pdf $>$. Acesso em 10 maio 2005.

OLIVEIRA, Djalma de Pinho Rebouças. Planejamento Estratégico. 13 ed. São Paulo: Atlas, 1999.

PADOVEZE, Clóvis Luís Padoveze. Controladoria Estratégica e Operacional. São Paulo: Pioneira Thomson Learning, 2003.

ROCHA, Augusto César Barreto. Configuração de um sistema de avaliação de desempenho alicerçado no Balanced Scorecard para uma indústria de confecções de porte médio. Dissertação (Mestrado em Engenharia de Produção) - UFSC, Florianópolis. 2002.

SANTOS, Ângela Maria M. M.; GUARNERI, Lucimar da Silva. Características Gerais do Apoio a Arranjos Produtivos Locais, BNDS Setorial, Rio de Janeiro, n. 12, pp. 195-204, set. 2000. 
SANTOS, Gustavo Antônio Galvão dos; DINIZ, José Eduardo; BARBOSA, Eduardo Kaplan. Aglomerações, Arranjos Produtivos Locais e Vantagens Competitivas Locacionais, Revista do BNDS, Rio de Janeiro, v. 11, n. 22, pp. 151-179, dez. 2004.

SEBRAE. Metodologia de Desenvolvimento de Arranjos Produtivos Locais: Projeto Promos - SEBRAE - BID: versão 2.0. Brasília: SEBRAE, 2004. 